\title{
Возможности сотрудничества ОБСЕ с Китаем: зачем и как?
}

\author{
Стефан Вольф и Штефани Лихтенштайн*
}

\section{Аннотация}

Каковы последствия растущего присутствия Китая для ОБСЕ? Это насущный вопрос для организации и ее государств-участников, учитывая важность отношений с Китаем и их всё более острый характер. Отвечая на этот вопрос, мы анализируем влияние китайской инициативы «пояса и пути» на три субрегиона ОБСЕ: Центральную Азию, Южный Кавказ и Восточную Европу и Западные Балканы. Наш анализ основан на широком круге источников, включая материалы, подготовленные по нашему заказу местными и региональными экспертами, доклады правительств и аналитических центров, а также обзор обширной вторичной литературы по данной теме. Мы пришли к выводу, что несмотря на то, что влияние китайской инициативы варьируется в зависимости от региона, ее реализация может иметь существенные геополитические и геоэкономические последствия, которые ОБСЕ не может игнорировать. На основе проведенного анализа мы предлагаем рекомендации по сотрудничеству ОБСЕ с Китаем и инициативой «пояса и пути».

Ключевые слова

Китай, инициатива «пояса и пути» (ИПП), ОБСЕ, взаимосвязанность, геополитика.

Для цитирования этой публикации: Вольф С., Лихтенштайн Ш. Возможности сотрудничества ОБСЕ с Китаем: зачем и как? // ОБСЕ Insights 2/2021 - Баден-Баден: Номос, 2022.

URL: https://doi.org/10.5771/9783748911463-02

\section{Введение}

За время, прошедшее с момента ее выдвижения в конце 2013 г., стратегия Китая по соединению Азии, Европы и Африки вдоль исторических маршрутов «Шелкового Пути» - инициатива «пояс и путь» (ИПП или «Инициатива») превратилась в масштабный проект глобального развития с возрастающими геополитическими и геоэкономическими последствиями. Выдвигая ИПП в своем выступлении в Казахстане в Университете имени Назарбаева, президент Китая Си Цзиньпин предложил

* Стефан Вольф, профессор кафедры политических наук и международных исследований, Университет Бирмингема, S.Wolff@bham.ac.uk.

Штефани Лихтенштайн, независимый журналист и дипломатический корреспондент, Вена, Австрия, office@stephanieliechtenstein.com. 
партнерам совместно с Китаем выстроить «Экономический пояс Шелкового Пути», «чтобы сделать экономические связи государств Евразии более тесными, их взаимное сотрудничество более глубоким, а пространство развития - более широким» ${ }^{1}$. Восемнадцать месяцев спустя, в марте 2015 г. Национальная комиссия по развитию и реформам КНР представила развернутый вариант предложенной в выступлении Си инициативы и уточнила, что цели ИПП заключаются в «укреплении взаимосвязанности азиатского, европейского и африканского континентов и прилегающих к ним морей, установлении и укреплении партнерских отношений между странами, расположенными вдоль «пояса и пути», создании всесторонней, многоуровневой и комплексной инфраструктурной взаимосвязанности и обеспечении диверсифицированного, независимого, сбалансированного и устойчивого развития этих стран» ${ }^{2}$.

Хотя некоторые из этих идей и целей были не совсем новыми, настоящим новшеством стало их систематическое объединение в один проект и стратегию. Важность Инициативы была подчеркнута в 2017 году, когда она была внесена в Конституцию Китайской Народной Республики, что сделало её неотъемлемой частью китайского государства и его политики ${ }^{3}$.

Сегодня ИПП не только считается центральным звеном внешней и экономической политики Китая, но и превратилась в комплексный стратегический инструмент китайского руководства, отражающий геополитические и геоэкономические устремления все более уверенной в себе и напористой мировой державы. К 2021 году в сотрудничестве в рамках ИПП принимали участие 140 государств и 30 международных организаций, а проекты реализовывались более чем в 70 странах. Более половины из пятидесяти семи государств-участников ОБСЕ подписали с Китаем меморандумы о взаимопонимании по сотрудничеству в рамках ИПП 4 .

То, что начиналось как «Экономический пояс Шелкового пути» и «Морской Шелковый путь XXI века», теперь также включает, в частности, «Полярный Шелковый путь», «Цифровой Шелковый путь» и «Шелковый путь здоровья» 5 . Повышение уровня амбициозности ИПП сказалось на оценках масштабов ее финансирования, которое, согласно произведенным в 2016 году расчетам Прйасвотерхаус Куперс, в предстоящие десять лет может составить «до 1 триллиона долларов США за счет государственного финансирования со стороны Китая» ${ }^{6}$. К концу 2020 года в трех субрегионах ОБСЕ были заключены инвестиционные и строительные контракты на общую сумму почти в 94 млрд долларов США: на 55 млрд долларов в Центральной Азии, на 21 млрд. на Южном Кавказе и в Восточной Европе и на 18 млрд - на Западных Балканах ${ }^{7}$.

ОБСЕ и ее государства-участники не могут больше позволить себе игнорировать значение и растущее присутствие Китая в регионе ОБСЕ и в соседних регионах. ИПП влияет на динамику геополитических и геоэкономических процессов, которые, в свою очередь, влияют на ОБСЕ как международный институт, отношения между ее государствами-участниками и на их отношения с Китаем. Это особенно очевидно в трех вышеупомянутых субрегионах, в которых Россия и Запад тради- 
ционно соперничали за влияние, в том числе в рамках проектов политической и экономической интеграции Европейского союза (ЕС) и Евразийского Экономического Союза (ЕАЭС). Хотя инициатива ИПП (пока) не предлагает аналогичные институциональные проекты интеграции, она представляет собой потенциальную долгосрочную - дополняющую, всеобъемлющую или конкурирующую - альтернативу ЕС и ЕАЭС. Это усугубляет проблемы, с которыми ОБСЕ уже сталкивается, в частности, в том, что касается её способности выполнять свой всеобъемлющий мандат в области безопасности в условиях, когда отношения между Россией и Западом деградировали до самого низкого уровня со времени окончания «холодной войны».

Соответственно, анализ осуществляемых Китаем в трех субрегионах проектов важен для оценки того, как ИПП на данном этапе повлияла на ОБСЕ. Он также позволяет рассмотреть возможные сценарии дальнейшего развития и предложить политические рекомендации относительно возможностей взаимодействия ОБСЕ с Китаем и с ИПП. Такое взаимодействие должно быть принципиальным, прагматичным и стратегическим, с тем чтобы сохранить приверженность государств-участников «концепции всеобъемлющей, основанной на сотрудничестве, равной и неделимой безопасности» ${ }^{8}$.

Наше рассмотрение влияния ИПП на ОБСЕ основывается на фактических данных и результатах анализа, представленных в опубликованном Сетью аналитических центров и академических институтов ОБСЕ комплексном докладе ${ }^{9}$, который опирается на восемнадцать подготовленных в рамках проекта национальными и региональными экспертами справочных материалов, научную литературу и политические документы по ИПП, а также на исходные первичные данные, почерпнутые, в частности, из источников Китая, России, ОБСЕ, ЕС, ООН и Всемирного банка. Поскольку работа над докладом была завершена в конце 2020 года, наш анализ был дополнен обобщением последних событий, результатов продолжающихся исследований и взаимодействием с экспертами.

Статья структурирована следующим образом. Сначала мы представляем результаты анализа присутствия и деятельности Китая в субрегионах Центральной Азии, Южного Кавказа и Восточной Европы, а также Западных Балкан. Затем мы обобщаем эти результаты в виде кратких выводов, которые, в свою очередь, составляют основу для наших политических рекомендаций.

\section{Центральная Азия}

Центральной Азии отводится ключевая роль в ИПП. С экономической точки зрения данный регион имеет критическое значение для автомобильного и железнодорожного транзитного сообщения между Китаем и европейскими рынками. Эти коммуникации представляют собой стратегически важную альтернативу существующим морским маршрутам. Китай также рассматривает экономическое развитие и ста- 
бильность в Центральной Азии как средство достижения важной политической цели - повышения уровня безопасности в соседней провинции Синьцзян, что, в свою очередь, должно способствовать минимизации негативных последствий развития событий в Афганистане ${ }^{10}$. Значение Центральной Азии отражается в уровне инвестиций Китая, которые не ограничиваются развитием транспортной инфраструктуры, а включают энергетический сектор, сырьевые отрасли и производство сельскохозяйственной продукции для нужд внутреннего потребления.

В регионе Центральной Азии ключевым партнером Китая является Казахстан. На его долю приходится почти две трети китайских средств, вложенных в регион с 2005 года. В Казахстане хорошо развита инфраструктура, страна политически относительно стабильна и имеет национальный план развития, который тесно увязан с ИПП, что делает ее привлекательной для китайских инвестиций. Китай вложил значительные средства в добычу нефти в Казахстане - китайские компании контролируют примерно 25\% этой отрасли. На Казахстан приходится примерно 75\% китайского импорта урана ${ }^{11}$.

С геополитической и стратегической точек зрения, развитие Центральной Азии важно для Китая, поскольку влияние ЕС и США здесь относительно невелико, что позволяет Китаю включить Центральную Азию в сферу своего влияния. В то время как Россия в настоящее является основным гарантом безопасности в регионе, Китай становится здесь доминирующим экономическим игроком. До настоящего времени Москва и Пекин придерживались такого негласного разделения труда, и обе стороны высоко оценивали сотрудничество между ними ${ }^{12}$. Одним из проявлений такого сотрудничества является торгово-экономическое соглашение между Китаем и ЕАЭС, участниками которого являются Казахстан и Кыргызстан, а также Армения, Беларусь и Россия. Хотя соглашение вступило в силу только в 2019 г., оно свидетельствует о потенциальных возможностях для углубления связей в будущем, особенно на фоне ужесточения позиции Запада в отношении как России, так и Китая.

\section{Южный Кавказ и Восточная Европа}

Географически отдаленные и не имеющие общей границы с Китаем государстваучастники ОБСЕ на Южном Кавказе (Армения, Азербайджан и Грузия) и в Восточной Европе (Беларусь, Молдова и Украина) имеют ряд общих характеристик, отличающих их от Центральной Азии и Западных Балкан.

Несмотря на индивидуальные отличия, эти страны в целом более развиты чем государства Центральной Азии. Однако в последнее десятилетие они отличались намного большей политической нестабильностью, чем страны Центральной Азии или Западных Балкан. Это очевидно на фоне продолжающегося конфликта в Украине, войны 2020 года между Арменией и Азербайджаном, оспариваемых результатов 
президентских выборов в Беларуси, которые сопровождались жестоким подавлением протестов. Помимо этого три страны (Грузия, Молдова и Украина) уже более десяти лет находятся в эпицентре политического и экономического соперничества между Россией и Западом ${ }^{13}$.

На фоне геополитической напряженности между Западом и Россией китайское присутствие в этом регионе было скромным по сравнению с Центральной Азией. Другие проблемы в регионе связаны с коррупцией и низким уровнем эффективности государственного управления. Основные мотивы деятельности Китая здесь во многом схожи с мотивами, которыми он руководствуется в двух других регионах: транзит и доступ к ресурсам.

В рамках концепции «Нового евразийского сухопутного моста» реализация ИПП способствовала осуществлению ряда крупных проектов в Беларуси, которая является для Китая неотъемлемой частью транзитного коридора на рынки ЕС через Казахстан, Россию и Беларусь. Китай также инвестировал средства в промышленные проекты (например, в белорусско-китайский индустриальный парк «Великий камень»). На сегодняшний день китайские банки предоставили белорусским компаниям кредиты на сумму 4,5 миллиардов долларов ${ }^{14}$.

С точки зрения фактических инвестиций сотрудничество Китая с Украиной значительно превосходит его сотрудничество с Беларусью. Так было и до, и после выдвижения ИПП. При этом потенциал для осуществления китайских проектов в Украине не был использован в полной мере из-за продолжающегося в стране конфликта и связанной с ним социальной, политической и экономической нестабильностью ${ }^{15}$.

Почти 70\% всех китайских инвестиций в Украине приходятся на период до официального выдвижения ИПП в 2013 году ${ }^{16}$. Они были сосредоточены в энергетическом секторе (солнечная энергия) и сельском хозяйстве (например, недавно построенный зерновой терминал в Николаеве, обеспечивающий украинский экспорт в Китай). Попытки Китая закрепиться в военно-промышленном комплексе Украины столкнулись с существенным противодействием со стороны Киева, как это было в случае с «Мотор Сич», производителем двигателей для военных самолетов.

Молдова же практически не интегрирована в ИПП, учитывая периферийное положение страны по отношению к основным экономическим коридорам, низкий уровень экономического развития, небольшой внутренний рынок и преимущественно аграрную экономику ${ }^{17}$.

Южный Кавказ не может предложить Китаю широкие возможности для обеспечения транспортной взаимосвязанности из-за отсутствия глубоководного порта в Грузии, несмотря на несколько предпринятых Китаем попыток построить для этой цели объекты в Анаклии ${ }^{18}$. В то же время Китай и Азербайджан подписали меморандум о взаимопонимании и другие двусторонние соглашения, результатом которых стал рост двусторонней торговли и пакет эконмических договоренностей, 
оцениваемый в 821 млн долларов и ориентированный на китайские инвестиции в нефтяной сектор Азербайджана ${ }^{19}$.

В Армении инвестиции были незначительными, но ситуация может измениться после заключения соглашения между Китаем и Арменией о создании «Умного города» стоимостью в 10-15 миллиардов долларов в течение следующих пятнадцати лет ${ }^{20}$.

\section{Западные Балканы}

Субрегион Западных Балкан включает Албанию, Боснию и Герцеговину, Косово, Северную Македонию, Сербию, Словению, Хорватию и Черногорию. Этот субрегион достиг значительно более высокого уровня развития, чем страны Центральной Азии, Южного Кавказа и Восточной Европы. В течение последней четверти века здесь в основном преобладало влияние Запада, которому Китай сейчас бросает вызов.

Главным мотивом включения Западных Балкан в ИПП является доступ к европейским рынкам. Поэтому развитие инфраструктуры на Западных Балканах считается стратегически важным для улучшения взаимосвязанности с ЕС.

Основные риски связаны здесь с неурегулированными последствиями сопровождавшегося вооруженными конфликтами распада бывшей Югославии, включая сохраняющуюся межэтническую напряженность и тлеющие пограничные споры. Для региона также характерны проблемы в области государственного управления, такие как коррупция и слабое верховенство закона.

На данный момент Сербия получила самую большую долю (60 процентов) китайских инвестиций в регионе. В то время как широкий спектр проектов был реализован в энергетическом секторе и в развитии местного транспорта, флагманским проектом ИПП в Сербии является строительство железной дороги Белград-Будапешт, связывающей столицы Сербии и Венгрии. Железная дорога является важным узлом на Балканском Шелковом пути от греческого порта Пирей до ЕС. Частичное строительство автомагистрали Белград-Южная Адриатика имеет такое же стратегическое значение.

В последние годы Белград и Пекин усилили сотрудничество по линии полиции. Наряды, состоящие из сербских и китайских полицейских, патрулируют в столице Сербии и других городах. Сербия - единственная страна в регионе, которой Китай продал военную технику и где проводились совместные военные и контртеррористические учения ${ }^{21}$.

Большинство других ключевых китайских проектов на Западных Балканах связаны с транспортной инфраструктурой, что подчеркивает значение региона как критически важного узла транспортного сообщения между Китаем и ЕС. К ним относятся автострада Арбер в Албании (соединяющая столицу Тирану с границей 
Северной Македонии), являющаяся частью транспортного коридора, призванного соединить побережье Ионического моря с болгарским побережьем Черного моря; Пелешацкий мост в Хорватии (строительство осуществляется Китайской корпорацией по строительству дорог и мостов, при софинансировании ЕС); автомагистраль Бар-Боляре в Черногории (соединяет город-порт Бар на побережье Адриатического моря с Сербией, финансируется за счет кредита Эксимбанка в размере 800 млн евро, что усугубляет и без того серьезную долговую проблему Черногории); автомагистрали Кичево-Охрид и Миладиновци-Штип в Северной Македонии (проходят вдоль транспортного коридора, соединяющего греческий порт Пирей со столицей Венгрии Будапешт), а также интеграция порта Копер в Словении в ИПП на основе соглашения с Нинбо Чжоушань Порт Груп с целью расширения судоходного сообщения и торговли.

Если китайские инвестиции и строительные контракты, заключенные в Хорватии и Словении, свидетельствуют о готовности и способности Китая соблюдать правила $\mathrm{EC}$, его основные вложения в Боснии и Герцеговине - в лигнитную электростанцию «Тузла-7» и электростанцию Станари, составившие в совокупности 1,3 миллиарда долларов, - идут вразрез с обязательством страны соблюдать правила ЕС в отношении государственной помощи и защиты окружающей среды.

\section{Выводы}

Растущее присутствие Китая в трех рассмотренных выше субрегионах свидетельствует о масштабах геополитических и геоэкономических последствий ИПП для ОБСЕ и ее государств-участников. Чтобы в полной мере оценить их значение и сформулировать соответствующие рекомендации, важно рассмотреть их в более широком контексте современных процессов в регионе ОБСЕ.

Отношения между Западом и Россией с одной стороны, и Западом и Китаем - с другой, продолжают ухудшаться. В то же время все государства-участники ОБСЕ и Китай разделяют общую заинтересованность в безопасности и стабильности на евроатлантическом и евразийском пространстве. Это представляет собой наиболее перспективную возможность для налаживания сотрудничества ОБСЕ и Китая. Однако в рамках такого сотрудничества влиятельность организации, в состав которой входят пятьдесят семь расположенных на евроатлантическом и евразийском пространстве государств-участников, в значительной степени будет зависеть от способности ОБСЕ подтвердить и возродить дух организации по обеспечению всеобъемлющей безопасности на основе сотрудничества.

На первый взгляд, Китай представляет собой привлекательную модель стабильного государственного управления и успешного внутреннего экономического развития и демонстрирует готовность и способность вносить вклад в глобальное управление и формировать его 22 . Возрастающее участие в предоставлении общественных 
благ повысило заинтересованность Китая в процессах формирования и обеспечения правил глобального управления. В силу преимущественной опоры на двусторонние соглашения в отличие от ЕС или ЕАЭС ИПП (пока) не является типичным интеграционным проектом с собственной системой регулирования, основанной на определенных правилах (как это имеет место в ЕС или ЕАЭС). Однако в будущем данная политика может измениться, и ИПП сможет конкурировать, а в перспективе и заменить существующие структуры международного управления.

На протяжении некоторого времени Китай отстаивал комплексное понимание безопасности. В своем выступлении на четвертом саммите Совещания по взаимодействию и мерам доверия в Азии (СВМДА) в Шанхае в 2014 году председатель КНР Си высказался за «общий, всеобъемлющий, основанный на сотрудничестве и устойчивый» подход к безопасности. Для Си всеобъемлющая безопасность означает «поддержание безопасности в традиционных и в нетрадиционных областях», включающих «этнические и религиозные проблемы [...], терроризм, трансграничную преступность, экологическую безопасность, кибербезопасность, энергетическую и ресурсную безопасность и крупные стихийные бедствия» ${ }^{23}$. Такое понимание безопасности было прочно интегрировано в ИПП. В своем отчете о реализации Инициативы в 2019 году Бюро группы управления по продвижению инициативы «пояс и путь» почти дословно воспроизвело формулу Си 2014 года, отметив, что «все страны должны содействовать цели общей, всеобъемлющей, основанной на сотрудничестве и устойчивой безопасности» ${ }^{24}$.

Существующие в ОБСЕ разногласия чреваты дальнейшим нарастанием дисфункциональности и неспособности реализовать ключевые положения ее всеобъемлющего мандата в области безопасности. Если это произойдет, государства-участники ОБСЕ, которые уже тесно сотрудничают с Китаем (например, страны Центральной Азии), или те, которые повернулись в сторону Китая по геополитическим и геоэкономическим причинам (например, Россия), могут счесть возглавляемые Китаем институты, такие как Шанхайская организация сотрудничества (ШОС), более надежной платформой для многостороннего сотрудничества по реализации ИПП. ШОС уже в точности повторяет некоторые части мандата ОБСЕ (хотя ей критически не хватает человеческого измерения) и дополняет ИПП, в частности, тем, что представляет собой многосторонний механизм для реагирования на риски в области безопасности. Как отметил в мае 2017 года Генеральный секретарь ШОС Рашид Алимов, с заключением соглашения о создании благоприятных условий для международных автомобильных перевозок ШОС оформила «правовую базу паритетных условий для автоперевозчиков» и заложила «единообразную основу осуществления международных автомобильных перевозок от Восточной Европы до восточных побережий России и Китая» ${ }^{25}$. Это ещё больше укрепило взаимодополняемость ШОС и ИПП. Такая взаимодополняемость в течение некоторого времени подчеркивалась китайскими, российскими и центральноазиатскими аналитиками, что может 
свидетельствовать о постепенном отказе России от оппозиции в пользу принятия действительно более широкого мандата ШОС 26.

По мере того как крупные державы продолжают преследовать свои интересы по расширению и сохранению соответствующих сфер влияния, а эти интересы всё больше определяют внешнюю политику в регионе ОБСЕ и по отношению к нему, потенциальная роль организации как форума для обсуждения этих разнонаправленных устремлений возрастает. Китай должен быть вовлечен в эти обсуждения, хотя это не обязательно предполагает необходимость его вступления в саму ОБСЕ. Удастся ли это сделать зависит от способности и желания государств-участников разработать и реализовать последовательную стратегию, которая будет лежать в основе такого подхода. Это, в свою очередь, зависит от реалистичной и основанной на фактах оценки современного присутствия Китая в регионе ОБСЕ и от понимания будущих сценариев развития.

\section{Рекомендации}

Хотя Китай делает акцент на экономическую составляющую ИПП и ее взаимовыгодный характер, такой грандиозный и амбициозный проект не может не иметь геополитических и геоэкономических последствий. Хотя пока неясно, какими будут эти последствия, когда и как они реализуются, будут ли они неизбежными или станут побочным следствием не артикулируемой Китаем долгосрочной стратегии, Китай и его ИПП представляют собой вызов, требующий ответа со стороны ОБСЕ.

Чтобы ответить на данный вызов, нужна реалистичная оценка перспектив конструктивного взаимодействия между ОБСЕ и Китаем. Для этого необходимо с самого начала обозначить три потенциальные проблемы. Во-первых, неясно, выиграют ли государства-участники от взаимодействия ОБСЕ с Китаем, поскольку это может ограничить выгоды, которые они получают от прямого двустороннего взаимодействия или от сотрудничества в таких форматах, как ЕС, ЕАЭС и ШОС. Во-вторых, взаимодействие с Китаем может оказаться несоразмерным вызовом для ОБСЕ. Учитывая и без того непростые отношения между государствами-участниками, это может ещё больше подорвать способность ОБСЕ выполнять ее мандат и поддерживать сформировавшийся нормативный консенсус. В-третьих, не ясно, захочет ли Китай сотрудничать с ОБСЕ и на каких условиях.

Эти проблемы не преуменьшают необходимость взаимодействия и не делают его невозможным. Скорее они задают параметры, в рамках которых может быть разработана и реализована стратегия взаимодействия. На основе приведенного выше анализа и более полного доклада Сети, на котором он основан, мы предлагаем следующие идеи для рассмотрения политиками ОБСЕ и её государствами-участниками. 
- Достижение минимального консенсуса по взаимодействию с Китаем Исполнительным структурам и институтам ОБСЕ, включая действующего Председателя и «тройку» председателей, следует начать с определения будущих сценариев развития отношений с Китаем. Использование сценарного планирования в качестве инструмента для достижения консенсуса и выработки политики может быть полезным для привлечения внимания государств-участников к последствиям присутствия и деятельности Китая. Оно способствовало бы формированию у них лучшего понимания соответствующих вызовов и возможностей и определению их позиции, не настаивая на примирении диаметрально противоположных взглядов на Китай. Таким образом, это могло бы стать основой для формирования минимального консенсуса в ОБСЕ по вопросу о возможности прагматического взаимодействия с Китаем.

- Применение принципиального, прагматического и стратегического подхода Прагматический подход к Китаю позволяет проводить политику многоканального взаимодействия, которая создает и использует возможности для диалога в областях, которые приоритетны для ОБСЕ, и в то же время открыта для обсуждения вопросов, которые может поставить Китай. Такой подход допускает возможность ситуативного и неформального сотрудничества.

В то же время прагматизм должен опираться на принципы ОБСЕ и руководствоваться стратегической перспективой, предполагающей установление на каком-то этапе официальных отношений с Китаем. В качестве первого шага речь могла бы идти о предоставлении Китаю статуса наблюдателя в ОБСЕ, а впоследствии - об установлении партнерских отношений, учитывающих масштабы и значение Китая. Саммит ОБСЕ в 2025 году мог бы стать подходящим форумом для формализации таких отношений.

- Поиск форматов для многостороннего взаимодействия

ОБСЕ следует рассмотреть взаимодействие с Китаем по линии ШОС по вопросам, представляющим взаимный интерес, включая борьбу с организованной преступностью (особенно наркотрафиком), защиту критически важной национальной и трансграничной инфраструктуры и стабилизацию положения в Афганистане. Речь могла бы идти о взаимодействии и по линии других международных организаций, например, СВМДА.

- Совместное управление воздействием на окружающую среду

Опираясь на существующие международные соглашения (такие как Орхусская конвенция 1998 года), ОБСЕ следует рассмотреть вопрос об инициировании официального диалога с Китаем по вопросам управления экологическими последствиями реализации ИПП для участвующих в ее реализации государств. В 
этом случае ОБСЕ могла бы предоставить площадку для обсуждения общих правил и принципов экологического управления.

- Разработка повестки дня взаимосвязанности 2.0

ОБСЕ следует рассмотреть вопрос о разработке новой программы транспортной взаимосвязанности, которая будет гарантировать, что в чем-то совпадающие (но не идентичные) подходы ОБСЕ, Китая, ЕС и ЕАЭС к решению задач взаимосвязанности могут стать и оставаться совместимыми и взаимодополняющими, несмотря на их различные нормативные основы. Это могло бы способствовать устойчивому и инклюзивному восстановлению после пандемии с упором на повышение устойчивости экономики, общества и институтов 27.

Достижение данной цели возможно только на основе коллективных усилий всех заинтересованных международных акторов. Используя свои возможности по организации встреч и формированию повестки дня ОБСЕ может предоставить площадку для обсуждения новых рациональных подходов к обеспечению непрерывного и свободного передвижения товаров, капитала, людей и идей, противодействию протекционистским тенденциям, и поддержанию эффективного и справедливого национального государственного управления и международного регулирования.

- Привлечение Китая к сотрудничеству по вопросам прав человека

В настоящее время существует мало возможностей для взаимодействия с Китаем по вопросам прав человека. Недавние действия Китая говорят сами за себя: первоначальное сокрытие вспышки коронавируса, подавление протестов в Гонконге и изменение его избирательной системы, попытки заставить замолчать защитников прав человека и аресты уйгуров и других мусульман тюркского происхождения в Синьцзяне.

Тем не менее, Китай отдает себе отчет в том, что хрупкие институты и слабое верховенство закона создают проблемы для реализации ИПП. Китай также понимает, что социальное и экономическое неравенство увеличивает недовольство и приводит к конфликтам и нестабильности. До сих пор ответом Китая на эти вызовы было экономическое развитие без какой-либо сопутствующей политической либерализации. Маловероятно, что его внутренняя политика изменится, и это не должно быть частью повестки дня ОБСЕ.

Общая заинтересованность в стабильности и безопасности создает возможности для налаживания сотрудничества с Китаем в рамках всеобъемлющего подхода, неотъемлемой частью которого является уважение прав человека и меньшинств. В контексте принципиального, прагматичного и стратегического подхода к взаимодействию с Китаем это имеет два последствия. Во-первых, человеческое измерение ОБСЕ не должно быть исключено из отношений между ОБСЕ и Китаем. 
Во-вторых, взаимодействие с Китаем не должно привести к ослаблению человеческого измерения в рамках всеобъемлющего подхода ОБСЕ к безопасности.

\section{Примечания}

1 President $\mathrm{Xi}$ Jinping delivers important speech and proposes to build a Silk Road Economic Belt with Central Asian countries // Ministry of Foreign Affairs of the People's Republic of China, 7 September 2013. URL: https://www.fmprc.gov.cn/mfa_eng/topics_665678/ xjpfwzysiesgjtfhshzzfh_665686/t1076334.shtml.

2 National Development and Reform Commission, Vision and Actions on Jointly Building Silk Road Economic Belt and 21st-Century Maritime Silk Road // Strategic Studies. - Vol. 4 (2014). No. 1. - P. 207.

3 Constitution of the Communist Party of China, Beijing, 24 October 2017. - P. 8.

4 Nedopil C. Countries of the Belt and Road Initiative // Green Belt and Road Initiative Center, 2021. URL: https://green-bri.org/countries-of-the-belt-and-road-initiative-bri/.

5 Официальной китайской карты ИПП больше не существует. Возможно, наиболее полная и точная картина представлена Институтом Меркатора по изучению Китая: Mapping the Belt and Road Initiative: This is where we stand // Mercator Institute for China Studies, 7 June 2018. URL. https://merics.org/en/analysis/mapping-belt-and-road-initiative-where-we-stand.

6 Van der Leer Y., Yau J. China's new Silk Route: The long and winding road // PwC, February 2016. - P. 4. URL: https://www.pwc.com/gx/en/growth-markets-center/assets/pdf/china-newsilk-route.pdf. Согласно анализу глобальных инвестиций и строительных контрактов Китая, проведенному Дереком Сиссором (Американский институт предпринимательства), совокупные финансовые обязательства Китая в период с 2005 г. составили более 2 трлн. долл. США. См.: Scissors D. China global investment tracker // American Enterprise Institute and Heritage Foundation, 2020. URL: https://www.aei.org/china-global-investment-tracker/.

7 Scissors D. Op. cit.

8 Астанинская юбилейная декларация: на пути к сообществу безопасности // Официальный сайт ОБСЕ. URL: https://www.osce.org/files/f/documents/d/8/74990.pdf.

9 Wolff S. China' s Belt and Road Initiative: Implications for the OSCE // OSCE Network of Think Tanks and Acacemic Institutions, March 2021. URL: https://osce-network.net/fileadmin/ user_upload/publications/China-BRI-Report-2021-fin.pdf.

10 Bitabarova A.G. Unpacking Sino-Central Asian Engagement along the New Silk Road: A Case Study of Kazakhstan // Journal of Contemporary East Asia Studies. - 2018. - No. 2. - P. 149-173; Pantucci R. China in Central Asia: The First Strand of the Silk Road Economic Belt // Asian Affairs. - 2019. - No. 2. - P. 202-215; Silin Y. et al. The Silk Road Economic Belt: Balance of Interests // Economic and Political Studies. - 2018. - No. 3. - P. 293-318.

11 Silin et al. Op. cit. - P. 306.

12 Gabuev A. Crouching Bear, Hidden Dragon: "One Belt One Road” and Chinese-Russian Jostling for Power in Central Asia // Journal of Contemporary East Asia Studies. - 2016. - No. 2. - P. 61-78; Baogang He. The Domestic Politics of the Belt and Road Initiative and Its Implications // Journal of Contemporary China. - 2019. - No. 116/ - P. 180-95.

13 Malyarenko T., Wolff S. The Logic of Competitive Influence-Seeking: Russia, Ukraine, and the Conflict in Donbas // Post-Soviet Affairs. - 2018. No. 4. - P. 191-212.

14 Malyarenko M. China's Belt and Road Initiative in the Contested Eastern Neighbourhood, неопубликованная статья. 
Там же.

16 Scissors D. Op. cit.

17 Malyarenko M. Op. cit.

18 Menabde G. Georgia's Anaklia deep-water port faces a new challenge // Eurasia Daily Monitor, 18 June 2019. URL: https://jamestown.org/program/georgias-anaklia-deep-water-port-faces-anew-challenge/; Daly J.C.K. Russia's discreet satisfaction over Georgia's Anaklia port debacle // Eurasia Daily Monitor, 16 March 2020. URL: https://jamestown.org/program/russias-discreetsatisfaction-over-georgias-anaklia-port-debacle/.

19 Baghirov O. Azerbaijan and China sign $\$ 800$ million economic package // Eurasia Daily Monitor, 29 May 2019. URL: https://jamestown.org/program/azerbaijan-and-china-sign-800million-economic-package-the-geo-economic-implications/

20 Kemoklidze N. Armenia, Azerbaijan and China’s BRI, неопубликованная статья.

21 Webber M. China and the Western Balkans: Opportunities and Challenges for NATO, неопубликованная статья.

22 В настоящее время Китай является вторым по величине финансовым донором операций $\mathrm{OOH} \mathrm{по} \mathrm{поддержанию} \mathrm{мира,} \mathrm{уступая} \mathrm{только} \mathrm{США} \mathrm{и} \mathrm{имея} \mathrm{долю} \mathrm{в} \mathrm{бюджете,} \mathrm{пре-}$ вышающую совокупный вклад России, Франции и Великобритании. См.: UN General Assembly, Implementation of General Assembly Resolutions 55/235 and 55/236, Report of the Secretary-General, Addendum, A/73/350/Add.1, 24 December 2018. URL: https:// undocs.org/A/73/350/Add.1. Азиатский банк инфраструктурных инвестиций, возглавляемый Китаем, на сегодняшний день привлек восемьдесят два региональных и нерегиональных участника и имеет чистые обязательства по инвестициям в размере более 8 млрд долл. США. См.: 2019 AIIB Annual Report and Financials // Asian Infrastructure Investment Bank. URL: https://www.aiib.org/en/news-events/annual-report/2019/_common/pdf/ 2019-aiib-annual-report-and-financials.pdf).

23 Xi Jinping. Remarks at the fourth summit of the Conference on Interaction and Confidence Building Measures in Asia // China.org.cn, 21 May 2014. URL: http://www.china.org.cn/world/ 2014-05/28/content_32511846.htm.

24 Office of the Leading Group for Promoting the Belt and Road Initiative. The Belt and Road Initiative: Progress, Contributions and Prospects, Beijing: Foreign Languages Press, 2019. - P. 50. URL: https://en.ndrc.gov.cn/newsrelease_8232/202002/P020200228350122318527.pdf.

25 Выступление Генерального секретаря ШОС Р. Алимова на Форуме ОБСЕ по сотрудничеству в области безопасности. Вена, 10 мая 2017 года. - С. 5 // Официальный сайт ОБСЕ. URL: https://www.osce.org/files/f/documents/c/f/316951.pdf.

26 Pan Dawei. SCO and strategic partnership between China and Russia // Valdai Club, 14 June 2018. URL: https://valdaiclub.com/a/highlights/sco-and-strategic-partnership/? sphrase id=902214; Khasanov U. The SCO and the transformation of modern political processes // Valdai Club, 7 November 2019. URL: https://valdaiclub.com/a/highlights/scoand-transformation-modern-political-processes/?sphrase_id=902214; Suslov D. Non-Western multilateralism: BRICS and the SCO in the post-COVID world // Valdai Club, 29 July 2020. URL: https://valdaiclub.com/a/highlights/non-western-multilateralism-brics-and-the-sco/? sphrase_id=1223135.

27 Под новой повесткой дня в области взаимосвязанности мы имеем в виду усовершенствованный вариант современной повестки дня ОБСЕ по взаимосвязанности. См.: Wolff S. China: A Challenge or an Opportunity for the OSCE? // Security and Human Rights Monitor, 22 April 2021. URL: https://www.shrmonitor.org/china-a-challenge-or-an-opportunity-for-theosce/. 
